REVIEW

\title{
The natural history of epilepsy: an epidemiological view
}

\author{
P Kwan, J W Sander
}

J Neurol Neurosurg Psychiatry 2004;75:1376-1381. doi: 10.1136/jnnp.2004.045690

Better information of the natural history of epilepsy has important implications for understanding the underlying neurobiology, evaluating treatment strategies, and planning healthcare resources. The traditional pessimistic view has been dispelled by results from modern community based prospective studies, showing that over $60 \%$ of newly diagnosed patients will enter remission upon treatment. Recent outcome studies suggest that medical intractability may be predicted after failure of two antiepileptic drugs. Poor prognostic factors include a high initial seizure density, symptomatic aetiology, and presence of structural cerebral abnormalities, all of which can be identified early on. Among patients who have entered remission, many will remain seizure-free after antiepileptic drug treatment is withdrawn, suggesting that the underlying seizure generating factor has remitted. Whether some of these patients have entered remission "spontaneously" is contentious because, with effective pharmacotherapy for epilepsy in use for over 100 years, the natural history of untreated epilepsy is largely unknown. Circumstantial evidence, mostly arising from resource poor countries where antiepileptic drug treatment is not readily available, indicates that spontaneous remission may occur in up to $30 \%$ of cases. Observations from these complementary sources suggest that, at the population level, prognosis of newly diagnosed epilepsy may be broadly categorised into three groups: remission without treatment, remission with treatment only, and persistent seizures despite treatment. As understanding of the prognostic factors improves, the potential of a "prognostic group specific" management approach should be explored so that effective treatments may be used in a more rational and targeted fashion.

See end of article for authors' affiliations

Correspondence to: Professor J W Sander, Department of Clinical and Experimental Epilepsy, UCL Institute of Neurology, Queen Square, London WC1N 3BG; Isander@ ion.ucl.ac.uk

Received 14 May 2004 Revised 29 June 2004 Accepted 29 June 2004
1 is increasingly recognised that, on an individual basis, the outcome of epilepsy strongly reflects the syndromic classification and underlying aetiology of the epilepsy. ${ }^{1-3}$ Consideration of the prognosis at population level, however, has important implications for the understanding of the underlying neurobiology, evaluation of treatment strategies, and planning of healthcare resources. Until very recently, the prognosis of epilepsy had been viewed with pessimism. Hippocrates believed that seizures beginning in adulthood lasted until death. ${ }^{4}$ Gowers 5 conceded that "the spontaneous cessation of seizures is an event too rare to be anticipated in any given case". Despite the availability of effective pharmacotherapy, heralded by the emergence of phenobarbital in 1912, Gowers's gloomy view was echoed by generations of researchers. For instance, in a survey in 1968, Rodin concluded that only $30 \%$ of patients with epilepsy ever achieved a two year remission. ${ }^{6}$ These studies, however, were small scale, hospital based, and retrospective. Results from recent prospective long term outcome studies have suggested a more favourable picture and greatly improved our understanding of the prognosis of epilepsy in response to treatment. In addition, epidemiological surveys from resource poor countries where anti-epileptic drug treatment is not readily available have shed important light on the course of untreated epilepsy.

We aim to provide an epidemiological interpretation of the evidence from these complementary sources of the "natural history" of epilepsy. Before the evidence is reviewed, it is important to appraise its strengths and weaknesses so that conclusions may be drawn in the appropriate context.

\section{SOURCES AND QUALITY OF EVIDENCE}

Epidemiology studies $v$ drug trials

As antiepileptic drug treatment is usually started at the point of diagnosis in the industrialised world, outcome studies carried out in these countries mostly reflect the prognosis of treated epilepsy. The prerequisite for an accurate assessment of the prognosis of treated epilepsy is the inclusion of patients at the point of treatment initiation with prospective follow up. Modern data fulfilling this requirement may be derived from two main sources: epidemiological studies and monotherapy drug trials. Data from the former are preferred as the latter are primarily designed to establish the efficacy of the test compounds, in most cases to satisfy regulatory requirements. These trials tend to enrol highly selected patients, some previously treated, with a relatively short duration of follow up. ${ }^{7}$ For instance, in the two Veterans Administration (VA) studies (which were non-regulatory), 25\% of the subjects were already on treatment at randomisation, most of them (approximately $90 \%$ ) were male, and head trauma was the single most common cause of seizures. ${ }^{8}{ }^{9}$ While the VA studies were pivotal in comparing the efficacy of the established antiepileptic drugs, results from such a selected sample of subjects clearly cannot be extrapolated to deduce the general outcome of epilepsy patients as a whole. In this review, we will not consider drug trials when evaluating the long term prognosis of treated epilepsy. 


\section{Community $\mathbf{v}$ centre based}

There have been several prospective epidemiological studies addressing the outcome of epilepsy in various settings, including specialist centres and primary care clinics in the community (table 1). Each of these settings has its advantages and disadvantages. Compared with the latter, studies done in the former can be expected to have a higher degree of diagnostic accuracy and consistency in treatment approach. However, referral bias can be of major concern in centre based studies; this can be rectified by the inclusion of patient cohorts that are as unselected as possible. ${ }^{16}$ As the diagnosis of epilepsy generally requires specialist assessment, ${ }^{17}$ community based studies at the primary care level may suffer from case ascertainment error. In some population based studies, diagnostic error was minimised by case note review by expert panels. ${ }^{13}$ Representative population based and centre based studies will both be considered in this review.

\section{Changes in definitions and treatment strategy over time}

The classification schemes of seizures and epilepsies currently in use were proposed in 1981 and 1989, respectively. ${ }^{18} 19$ Direct comparison between studies carried out before these schemes were widely adopted and the more recent ones could raise problems when analysing the effect of seizure type and epilepsy syndrome on prognosis. Additional methodological concerns in studies of long follow up duration may occur because the number of antiepileptic drugs available has increased dramatically over the past two decades while the time for initiating treatment has generally been delayed from the first seizure to at least the second attack. ${ }^{20}$ The preferred treatment approach for newly diagnosed patients has also changed from polytherapy to monotherapy since the late 1970s/early 1980s. However, such concerns are likely to be ill founded as there is no evidence to support the view that these changes in treatment strategy have made a significant impact on the long term prognosis of epilepsy. Available human data suggest that, while antiepileptic drugs are effective in suppressing seizures, they do not alter the underlying epileptogenic process. ${ }^{21} 22$

\section{Resource-poor countries}

In contrast to the industrialised countries, antiepileptic drug treatment is not widely available in resource-poor countries, for various reasons. Indeed, it is estimated that $85 \%$ of epilepsy sufferers living in resource-poor countries do not receive any treatment. ${ }^{23-25}$ Epidemiologists have capitalised on the large proportion of untreated patients in this setting to study the "true" natural history of epilepsy. ${ }^{26}$ It is important, however, to note the circumstantial nature of the evidence gathered in these retrospective surveys. In addition, case definitions used might not conform to international guidelines and, owing to lack of investigational procedures, classification is almost entirely semiological. Therefore, results from these studies should not be used to derive firm conclusions but are best regarded as a basis for hypothesis generation.

\section{REMISSION OF TREATED EPILEPSY}

The first series of studies that provided a more accurate and positive assessment of the natural history of treated epilepsy was a community based project carried out in Rochester, Minnesota, USA. In this retrospective study, patients were identified from the Mayo Clinic record linkage system which included all medical contacts of residents of Olmsted County, Minnesota, since 1935. ${ }^{27}$ Results primarily concerning the incidence, prevalence, and causes of seizures and epilepsy have been published in a series of reports, covering the periods from 1935 to $1967,{ }^{28} 1940$ to $1980,{ }^{29} 1935$ to $1984,{ }^{30}$ 1980 to $1984,{ }^{31}$ and as summary articles for the 50 year period. $^{27} 32$ The issues of remission and early prognostic factors were explored in two reports. ${ }^{11}{ }^{33}$ In the initial examination, the probability of being in remission for five years at 20 years after diagnosis (that is, terminal remission) was $70 \% .^{33}$ This was revised to $75 \%$ in the more recent analysis. ${ }^{11}$ Predictors of a better outcome were absence of early life brain damage, absence of generalised epileptiform activity on EEG, and no history of generalised tonic-clonic seizures. The predictive value of these factors, however, was weak. ${ }^{11}$

The National General Practice Study of Epilepsy (NGPSE) conducted in the United Kingdom is the largest ongoing prospective community based study of the prognosis of epileptic seizures. ${ }^{34-36}$ Patients with newly diagnosed confirmed or suspected epilepsy were identified from 275 general practices throughout the UK between 1984 and 1987. Cumulative remission rates-that is, actuarial estimates of percentage seizure-free at any time during follow up-and terminal remission rates for various durations at various time intervals were calculated. At a median follow up of 7.1 years, among the 564 patients with "definite" epilepsy, the chance of ever achieving five year remission after nine years from diagnosis was $68 \%$, and $54 \%$ of patients were in five year terminal remission. ${ }^{13}$ Even when patients with acute symptomatic seizures and those who had only one seizure were excluded, $60 \%$ had achieved a five year remission by nine years of follow up. ${ }^{37}$ Analysis of prognostic factors showed that only the number of seizures occurring in the first six months after presentation predicted the chance of remission. ${ }^{38}$ The higher the "seizure density" within this initial phase of the seizure disorder, the less likely was it for the patients to enter remission. Other modern large scale studies that include only newly diagnosed patients followed up for long periods also tend to suggest a remission rate of $60-80 \%$ (table 1).

\section{OUTCOME WITH RESPECT TO TREATMENT COURSE}

These studies have provided a more accurate estimation of the probability of long term remission in relation to time from diagnosis; analysis of prognostic factors was, however,

\begin{tabular}{|c|c|c|c|c|c|c|}
\hline Reference & Study setting & Special study features & $\begin{array}{l}\text { No of } \\
\text { patients }\end{array}$ & $\begin{array}{l}\text { Median follow up } \\
\text { (years) }\end{array}$ & $\begin{array}{l}\text { Years in } \\
\text { remission }\end{array}$ & $\begin{array}{l}\% \text { in remission at } \\
\text { median follow up }\end{array}$ \\
\hline $\begin{array}{l}\text { Elwes et al }\left.\right|^{10} \\
\text { Shafer et al }{ }^{11} \\
\text { Collaborative Group }{ }^{12} \\
\text { Cockerell et al } \\
\text { Sillanpaa et al } \\
\text { Lindsten et al }{ }^{15}\end{array}$ & $\begin{array}{l}\text { Hospital } \\
\text { Community } \\
\text { Hospital } \\
\text { Community } \\
\text { Hospital } \\
\text { Community }\end{array}$ & $\begin{array}{l}\text { Definite epilepsy } \\
\text { Children only } \\
\geqslant 1 \text { baseline seizure } \\
\geqslant 2 \text { baseline seizures }\end{array}$ & $\begin{array}{l}106 \\
432 \\
280 \\
564 \\
176 \\
107 \\
89\end{array}$ & $\begin{array}{c}5.5 \\
17 \\
4 \\
7 \\
28 \\
9 \\
9\end{array}$ & $\begin{array}{l}2 \\
5 \\
1 \\
5 \\
1 \\
5 \\
5\end{array}$ & $\begin{array}{l}79 \\
66 \\
70 \\
68 \\
80 \\
64 \\
58\end{array}$ \\
\hline
\end{tabular}


often undertaken irrespective of treatment status. None specifically addressed the relation between outcome and the course of antiepileptic drug treatment-that is, examining outcome with "drug treatment regimens" as the variable instead of "time". Undoubtedly, it is important to the patient to know the likelihood of seizure freedom at various time points after the onset of seizures or diagnosis. However, the great majority of patients, at least in the developed countries, are started on antiepileptic drug treatment when a diagnosis of epilepsy is made. From a practical point of view, it would also be useful to gauge the chance of success with the first antiepileptic drug chosen as well as that of any successive regimens if it fails. When the first drug fails to control the epilepsy, as is often the case, little is known about the proportion of patients responding to subsequent monotherapy or combination treatment, and whether there is any difference in efficacy between these two treatment strategies. Such poor documentation of progress in response to treatment has resulted in confusion and lack of consensus over the definition of "refractory" epilepsy ${ }^{39} 40$ and has hindered the development of a rational approach to management.

The relation between outcome and course of antiepileptic drug treatment has been examined specifically in an ongoing long term study of newly diagnosed patients conducted in Glasgow, Scotland, since 1982. In the first analysis reported in 2000, 525 unselected adolescent and adult patients with a new diagnosis of epilepsy were started on antiepileptic drug treatment and followed for up to 16 years (median five years). ${ }^{16}$ Among the 470 patients who had never previously received antiepileptic drug treatment, $64 \%$ entered terminal remission of at least one year. Response to the first antiepileptic drug was the most powerful predictor of prognosis. Among the 248 patients in whom the first drug was unsuccessful, only $79(32 \%)$ subsequently became seizure-free. Indeed, only $11 \%$ of the 113 patients in whom the first drug failed primarily because of lack of efficacy (as opposed to adverse events or other causes) later became seizure-free. The predictability of "failure of first antiepileptic drug trial" for future refractory epilepsy has also been demonstrated in a retrospective study of children with temporal lobe epilepsy. ${ }^{41}$

When the outcome in response to treatment course was examined in the Glasgow study, it was found that $47 \%$ of patients became and remained seizure-free on the first drug, $13 \%$ on the second drug, but only $4 \%$ on the third drug or a combination of two drugs ${ }^{16}$ (table 2$)$. Thirty five patients $(7 \%$ of the total population) who responded to the first or second monotherapy were able to withdraw from treatment and remained seizure-free. In a follow up analysis it was shown that, of those who became seizure-free on the first drug, over $90 \%$ did so on relatively moderate dosing (daily doses of 800 $\mathrm{mg}$ or less of carbamazepine, $1500 \mathrm{mg}$ or less of sodium valproate, and $300 \mathrm{mg}$ or less of lamotrigine). ${ }^{42}$

Results from the Glasgow studies support the hypothesis that patients with newly diagnosed epilepsy comprise two distinct populations which can be identified early in the

Table 2 Success of antiepileptic drug regimens in $\mathbf{4 7 0}$ patients with newly diagnosed previously untreated epilepsy

\begin{tabular}{lrr}
\hline Variable & \multicolumn{1}{c}{ n } & \multicolumn{1}{c}{$\%$} \\
\hline Seizure-free on first monotherapy & 222 & 47 \\
Seizure-free on second monotherapy & 61 & 13 \\
Seizure-free on third monotherapy & 6 & 1 \\
Seizure-free on two drugs & 12 & 3 \\
Total seizure-free & 301 & 64 \\
\hline Data taken from Kwan and Brodie, 2000. & \\
\hline
\end{tabular}

course of the treatment paradigm. ${ }^{43}$ Around $60 \%$ of patients have a good prognosis. They will become seizure-free on a modest or moderate dose of the first or second choice antiepileptic drug as monotherapy without developing intolerable side effects. In some patients, the antiepileptic drug may subsequently be withdrawn without relapse of seizures, suggesting that the underlying seizure generating factor has indeed remitted. The hypothesis that newly diagnosed patients may comprise two distinct populations de novo is supported by recent pharmacogenetic data demonstrating that certain genetic variants may be associated with medical intractability ${ }^{44}$ or even with the outcome of epilepsy surgery. ${ }^{45}$

\section{REMISSION AFTER SUBSEQUENT DRUG WITHDRAWAL}

Whether, and to what extent, treatment can be successfully withdrawn in patients who have become seizure-free on antiepileptic drug treatment has been examined in several retrospective and prospective studies including both paediatric and adult patient populations ${ }^{46}$ Using specific methodological criteria, Berg and Shinnar ${ }^{47}$ systematically reviewed 25 reports and concluded that the typical estimate of risk of relapse was $25 \%$ at one year after initiating antiepileptic drug withdrawal and $29 \%$ at two years. However, these studies probably suffered from significant selection bias and might have underestimated the relapse rate as many were small scale and retrospective, and all but one were uncontrolled. In addition, although estimating the risk of relapse after initiating (not completing) the discontinuation of antiepileptic drugs is of practical value, the meta-analysis did not address the actual proportion of patients able to remain seizure-free after complete withdrawal of treatment, which suggests remission of the underlying seizure generating factor.

The only large scale randomised controlled trial to compare the policies of continued antiepileptic drug treatment versus slow discontinuation of treatment is the multicentre MRC Antiepileptic Drug Withdrawal Study conducted in the United Kingdom. ${ }^{48}$ Even in this large study, there was substantial self selection on the part of the patients, with 776 eligible subjects refusing to be randomised, the most important reason being possession of a driving licence. One thousand and thirteen patients who had been seizure-free for at least two years (median three years) were randomised to either policy, and followed up for between one and five years. Complete discontinuation was achieved in 373 patients $(73 \%)$ in the slow withdrawal group. Among these, 260 $(70 \%)$ remained in remission.

Combining the data from these pivotal studies, it could be inferred that, at a conservative estimate, at least $60 \%$ of newly diagnosed patients will enter long term remission on treatment initiation. Of these, $70 \%$ will be able to withdraw from antiepileptic drugs, and $70 \%$ of these will remain seizure-free. Thus, in approximately $30 \%$ (70\% of $70 \%$ of $60 \%$ ) of newly diagnosed patients, after receiving antiepileptic drug treatment of variable duration, the epileptogenic factor will eventually cease to exist or function.

\section{SPONTANEOUS REMISSION?}

It is widely accepted that the currently available antiepileptic drugs are anti-seizure rather than anti-epileptogenic-that is, they are effective in suppressing the symptoms (seizures) but they do not alter the underlying disease process (epileptogenesis) or its long term prognosis. ${ }^{21} 22$ Although an antiepileptogenic or disease modifying effect has been noted for some antiepileptic drugs in selected animal models ${ }^{49}{ }^{50}$ such an effect has not been found in clinical trials. Results of antiepileptic drug prophylaxis studies among patients with febrile seizures, ${ }^{51}{ }^{52}$ severe head injury, ${ }^{53}{ }^{54}$ and craniotomy ${ }^{55}$ 
suggest that, despite suppressing immediate seizures, prophylactic antiepileptic drug treatment does not reduce the risk of the development of epilepsy in the long term.

Early treatment with antiepileptic drugs does not seem to improve long term prognosis either. ${ }^{56}$ In the Italian FIRST study, 419 patients were randomised to immediate antiepileptic drug treatment after the first generalised tonicclonic seizure or to delayed treatment initiation until a recurrence had occurred. Although the likelihood of seizure relapse was lower in the former group, both groups had the same time dependent probability of one and two year remission after starting treatment. ${ }^{57}$ In a community based study in Kenya, 249 untreated patients completed a treatment programme with either carbamazepine or phenobarbital monotherapy for 12 months. ${ }^{58}$ Although $53 \%$ of the patients had had recurrent seizures for over five years and $68 \%$ had had more than 10 seizures in the year before recruitment, altogether $53 \%$ were seizure-free in the last six months of treatment. There was no association between the remission rate and either the duration of epilepsy or the total number of lifetime seizures in this cohort.

It is therefore possible that among the $30 \%$ of newly diagnosed patients who are able to remain in remission after eventual drug withdrawal, the epileptogenic process has remitted spontaneously, regardless of treatment. Although this is an important issue with far reaching implications for the understanding of the neurobiology of epilepsy and for the valid interpretation of antiepileptic drug trials, the possibility of spontaneous remission of epilepsy has attracted relatively little attention from researchers. ${ }^{1}$ This is probably because of ethical concerns about conducting a scientifically valid study to test this hypothesis. The true spontaneous remission rate can only be ascertained accurately by randomly assigning newly diagnosed patients to treatment or no treatment; such a protocol is difficult to justify ethically, as effective treatment has been available since 1857 and, in developed countries, antiepileptic drug treatment is usually begun immediately after diagnosis. Current evidence on the natural history of untreated epilepsy is therefore circumstantial, mostly emerging from resource-poor countries where treatment is not widely available.

\section{NATURAL HISTORY OF UNTREATED EPILEPSY}

A household survey in the highlands of northern Ecuador in the late 1980s identified 1029 people with a probable or definite history of epilepsy, $11 \%$ of whom had had a single episode. ${ }^{59}{ }^{60}$ Among the 643 patients who had never received antiepileptic drug treatment, 314 (49\%) had been seizure-free for at least the previous 12 months. Thus $31 \%$ of the whole patient population had entered remission spontaneously. Even this was likely to be an underestimation because, in population surveys, people whose epilepsy is in remission are more likely to be missed than those with active epilepsy.

Another piece of evidence suggesting that spontaneous remission of epilepsy occurs in a substantial proportion of patients is the similar prevalence rates in resource-poor and developed countries. This is despite the fact that many patients in the former have never received antiepileptic drug treatment. ${ }^{26}$ A recent WHO commissioned household survey in rural regions of China identified 387 patients with definite epilepsy among 55616 inhabitants. ${ }^{61}$ The prevalence rate of $7 / 1000$ is comparable with those of developed countries. ${ }^{26}$ Of those with active epilepsy, 63\% were not under treatment ("treatment gap"), and of the 130 patients with inactive epilepsy, $41 \%$ had never been treated. It has been argued that the similar prevalence rates in resource-poor and developed nations partly reflects the higher mortality of epilepsy and shorter life expectancy in the former countries, but the average life expectancy of the Chinese population reached

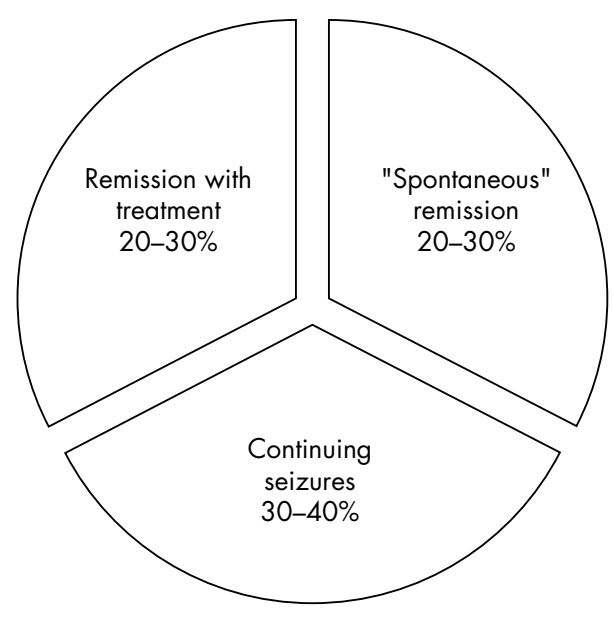

Figure 1 Natural history of newly diagnosed epilepsy.

71.2 years in $2001 .{ }^{62}$ It is more likely that the main reason is the occurrence of spontaneous remission in many untreated cases.

It may be argued that data from resource-poor countries may not apply to the developed world because the aetiology of epilepsy may be different. In a Finnish study, 33 patients were retrospectively identified at a teaching hospital who had presented with two or more unprovoked seizures for which they had never received antiepileptic drug treatment, and it was found that $42 \%$ had entered a two year remission by 10 years after onset. ${ }^{63}$ The study was limited by its small sample size and the likely bias that, in developed countries where treatment is readily available, patients with mild disease are more inclined to reject treatment. Nevertheless, the study showed that spontaneous remission of epilepsy has also been observed in developed countries.

\section{AN EPIDEMIOLOGICAL INTERPRETATION}

Observations from the above studies lend support to the suggestion that, at population level, prognosis of newly diagnosed epilepsy may be broadly categorised into three groups, reflecting the underlying neurobiological process (fig 1 ).

Group 1. Excellent prognosis-In 20-30\% patients, the condition enters long term remission after a variable period of time and level of activity, probably even without antiepileptic drug treatment. If treated, these patients become seizure-free on the first or second monotherapy, often requiring no more than moderate doses, which can be successfully withdrawn after a period of seizure freedom. The primary aim of antiepileptic drug treatment, if indicated, in this group of patients is to suppress seizures until "spontaneous" remission occurs, as seizures themselves are not benign and may cause considerable morbidity or even mortality. Epilepsy syndromes that fall into this category include benign neonatal seizures, benign rolandic epilepsy, and childhood absence epilepsy.

Group 2. Remission with treatment only-The $20-30 \%$ of patients comprising the second group become, and remain, seizure-free only with continuing antiepileptic drug treatment. Some may require more than one antiepileptic drug and multiple attempts may be needed to find the right combination for the individual patient. The epileptogenic process does not truly remit and seizures recur if treatment is withdrawn. Continuing antiepileptic drug treatment is required to suppress seizure relapse. Examples of this group may include juvenile myoclonic epilepsy, and the bulk of the localisation related epilepsies. 
Group 3. Continuing seizures despite treatment-In the remaining $30-40 \%$ of patients, seizures recur in varying degrees of intensity and frequency despite antiepileptic drug treatment. Some patients have frequent debilitating seizures qualifying as having "refractory" epilepsy. ${ }^{64}$ Antiepileptic drug treatment can, at best, only ameliorate the severity or frequency of seizures. Conditions in this category include many symptomatic/cryptogenic localisation related epilepsies such as those associated with mesial temporal sclerosis, cortical dysplasia, gross structural brain lesions, the progressive myoclonic epilepsies, and West syndrome.

In practice, subgroups may be observed within these three broad categories. For instance, among patients belonging to the first prognostic group, although many enter remission "spontaneously", some seem to need a small, often starting dose of an antiepileptic drug, and do not have another seizure after receiving the first dose of their first ever antiepileptic drug ${ }^{65}{ }^{66}$ Patients in the second prognostic group may also be further subdivided into those who remain seizure-free on monotherapy, and those who require several attempts of antiepileptic drug combinations before the "right" regimen is found.

It should be emphasised that, at the individual level, the natural history of epilepsy may be highly variable, depending upon the underlying syndromic classification and aetiology. A notable example is mesial temporal lobe epilepsy associated with hippocampal sclerosis, for which growing evidence suggests a progressive course in some patients. ${ }^{67}{ }^{68}$ Accumulating data, mostly derived from histopathological ${ }^{69}$ and imaging models ${ }^{70}$ of temporal lobe epilepsy, suggest that recurrent seizures may induce long lasting neuronal injury. It remains to be seen whether these neuronal changes actually result in perpetuating seizures. In a retrospective survey of 333 patients who underwent resective surgery for medically refractory epilepsy ( $88 \%$ had anterior temporal lobectomy), the average time to failure of two first line antiepileptic drugs was 9.1 years (median five years). Twenty six per cent of 284 patients from the cohort recalled a previous period of at least one year seizure freedom since the onset of epilepsy. ${ }^{71}$ This suggests that for some patients with temporal lobe epilepsy, medical intractability may not declare itself in the early stage of the disorder. Clearly, as epilepsy is not a single disease, syndrome/aetiology specific prospective prognostic studies are needed if we are to manage individual patients in a more rational fashion.

\section{IMPLICATIONS FOR CLINICAL RESEARCH PARADIGM}

This conceptual framework has important implications for the formulation of a "prognostic group based" approach to the management of newly diagnosed epilepsy. With few exceptions, the established and newer antiepileptic drugs have shown similar efficacy in comparative monotherapy studies recruiting newly diagnosed patients. ${ }^{7}$ The difficulty in finding differences in efficacy among the various antiepileptic drugs for these patients might be partly explained by the spontaneous remission in a substantial proportion of cases. Targeting those with a probable poorer prognosis might increase the chance of detecting differences in efficacy in a head to head monotherapy trial.

With mounting circumstantial evidence of eventual spontaneous remission in a substantial proportion of newly diagnosed patients, the objections on ethical grounds to conducting randomised placebo controlled trials in this patient population may require re-evaluation. It could be argued that routine prescription of antiepileptic drugs, with a catalogue of potential side effects, ${ }^{72}$ to the many newly diagnosed patients who may enter remission spontaneously raises ethical concern. This applies particularly to those without poor prognostic factors-that is, those without structural brain abnormalities, high initial seizure density, or abnormal EEG findings. ${ }^{16}{ }^{38} 39$ Targeting these patients in a placebo controlled study would minimise the risk of recurrent seizures.

\section{CONCLUSIONS}

The natural history of epilepsy remains poorly understood. Complementary data from developed and resource-poor countries suggest that spontaneous remission occurs in a substantial proportion of patients. While seizures may be controlled by antiepileptic drug treatment in some patients, others remain refractory to medical treatment. Accumulating evidence supports the suggestion that, at the population level, newly diagnosed patients may be categorised from onset into three broad groups of treatment outcome based on clinical characteristics. As our understanding of these prognostic factors improves, the potential of a "prognostic group specific" approach for the management of newly diagnosed epilepsy should be explored so that effective treatment may be used in a more rational and targeted fashion. ${ }^{73}$

\section{Authors' affiliations}

P Kwan, Division of Neurology, Department of Medicine and Therapeutics, The Chinese University of Hong Kong, Prince of Wales Hospital, Shatin, Hong Kong

J W Sander, Department of Clinical and Experimental Epilepsy, UCL Institute of Neurology, Queen Square, London WCIN 3BG, UK

Competing interests: none declared

\section{REFERENCES}

1 Sander JW. Some aspects of prognosis in the epilepsies: a review. Epilepsia 1993;34:1007-16.

2 Berg AT, Shinnar S. Do seizures beget seizures? An assessment of the clinical evidence in humans. J Clin Neurophysiol 1997; 14:102-10.

3 Semah F, Picot MC, Adam C, et al. Is the underlying cause of epilepsy a major prognostic factor for recurrence? Neurology 1998;51:1256-62.

4 Temkin O. The falling sickness: a history of epilepsy from the Greeks to the beginnings of modern neurology, 2nd ed. Baltimore: Johns Hopkins, 1971.

5 Gowers WR. Epilepsy and other chronic convulsive diseases. London: Churchill, 1881.

6 Rodin E. The prognosis of patients with epilepsy. Springfield: Charles C Thomas, 1968.

7 Kwan P, Brodie MJ. Clinical trials of antiepileptic medications in newly diagnosed patients with epilepsy. Neurology 2003;60(suppl 4):S2-12.

8 Mattson RH, Cramer JA, Collins JF, et al. Comparison of carbamazepine, phenobarbital, phenytoin, and primidone in partial and secondarily generalized tonic-clonic seizures. N Engl J Med 1985;313:145-51.

9 Mattson RH, Cramer JA, Collins JF. A comparison of valproate with carbamazepine for the treatment of complex partial seizures and secondarily generalized tonic-clonic seizures in adults. The Department of Veterans Affairs Epilepsy Cooperative Study No 264 Group. N Engl J Med 1992;327:765-71.

10 Elwes RD, Johnson AL, Shorvon SD, et al. The prognosis for seizure control in newly diagnosed epilepsy. N Engl J Med 1984;311:944-7.

11 Shafer SQ, Hauser WA, Annegers JF, et al. EEG and other early predictors of epilepsy remission: a community study. Epilepsia 1988;29:590-600.

12 Prognosis of epilepsy in newly referred patients: a multicenter prospective study of the effects of monotherapy on the long-term course of epilepsy. Collaborative Group for the Study of Epilepsy. Epilepsia 1992;33:45-51.

13 Cockerell OC, Johnson AL, Sander JW, et al. Remission of epilepsy: results from the National General Practice Study of Epilepsy. Lancet 1995;346:140-4

14 Sillanpaa $M$, Jalava $M$, Kaleva $O$, et al. Long-term prognosis of seizures with onset in childhood. N Engl J Med 1998;338:1715-22.

15 Lindsten $\mathrm{H}$, Stenlund H, Forsgren L. Remission of seizures in a populationbased adult cohort with a newly diagnosed unprovoked epileptic seizure. Epilepsia 2001;42:1025-30.

16 Kwan P, Brodie MJ. Early identification of refractory epilepsy. N Engl J Med 2000;342:314-19.

17 SIGN. Diagnosis and management of epilepsy in adults. Edinburgh, Scottish Intercollegiate Guidelines Network, Royal College of Physicians, 2003.

18 The Commission for classification and terminology of the International League Against Epilepsy. Proposal for revised clinical and electroencephalographic classification of epileptic seizures. Epilepsia 1981;22:489-501.

19 Anon. Proposal for revised classification of epilepsies and epileptic syndromes. Commission on Classification and Terminology of the International League Against Epilepsy. Epilepsia 1989;30:389-99. 
20 Brodie MJ, Dichter MA. Antiepileptic drugs. NEngl J Med 1996;334:168-75.

21 Temkin NR. Antiepileptogenesis and seizure prevention trials with antiepileptic drugs: meta-analysis of controlled trials. Epilepsia 2001;42:515-24.

22 Schachter SC. Current evidence indicates that antiepileptic drugs are anti-ictal, not antiepileptic. Epilepsy Res 2002;50:67-70.

23 Scott RA, Lhatoo SD, Sander JW. The treatment of epilepsy in developing countries: where do we go from here? Bull WHO 2001;79:344-51.

24 Meinardi H, Scott RA, Reis R, et al. The treatment gap in epilepsy: the current situation and ways forward. Epilepsia 2001;42:136-49.

25 Kale R. Global Campaign Against Epilepsy: the treatment gap. Epilepsia 2002;43(suppl 6):31-3.

26 Sander JW, Shorvon SD. Epidemiology of the epilepsies. J Neurol Neurosurg Psychiatry 1996;61:433-43.

27 Annegers JF, Rocca WA, Hauser WA. Causes of epilepsy: contributions of the Rochester epidemiology project. Mayo Clin Proc 1996;71:570-5.

28 Hauser WA, Kurland LT. The epidemiology of epilepsy in Rochester, Minnesota, 1935 through 1967. Epilepsia 1975;16:1-66.

29 Hauser WA, Annegers JF, Kurland LT. Prevalence of epilepsy in Rochester, Minnesota: 1940-1980. Epilepsia 1991;32:429-45.

30 Hauser WA, Annegers JF, Kurland LT. Incidence of epilepsy and unprovoked seizures in Rochester, Minnesota: 1935-1984. Epilepsia 1993;34:453-68.

31 Zarrelli MM, Beghi E, Rocca WA, et al. Incidence of epileptic syndromes in Rochester, Minnesota: 1980-1984. Epilepsia 1999;40:1708-14.

32 Hauser WA, Annegers JF, Rocca WA. Descriptive epidemiology of epilepsy: contributions of population-based studies from Rochester, Minnesota. Mayo Clin Proc 1996;71:576-86.

33 Annegers JF, Hauser WA, Elveback LR. Remission of seizures and relapse in patients with epilepsy. Epilepsia 1979;20:729-37.

34 Hart YM, Sander JW, Shorvon SD. National General Practice Study of Epilepsy and Epileptic Seizures: objectives and study methodology. Neuroepidemiology 1989;8:221-7.

35 Sander JW, Hart YM, Johnson AL, et al. National General Practice Study of Epilepsy: newly diagnosed epileptic seizures in a general population. Lancet 1990;336:1267-71.

36 Hart YM, Sander JW, Johnson AL, et al. National General Practice Study of Epilepsy: recurrence after a first seizure. Lancet 1990;336:1271-4.

37 Cockerell OC, Johnson AL, Sander JW, et al. Prognosis of epilepsy: a review and further analysis of the first nine years of the British National General Practice Study of Epilepsy, a prospective population-based study. Epilepsia 1997;38:31-46.

38 MacDonald BK, Johnson AL, Goodridge DM, et al. Factors predicting prognosis of epilepsy after presentation with seizures. Ann Neurol 2000;48:833-41.

39 Perucca E. Pharmacoresistance in epilepsy: how should it be defined? CNS Drugs 1998;10:171-9.

40 Regesta G, Tanganelli P. Clinical aspects and biological bases of drugresistant epilepsies. Epilepsy Res 1999;34:109-22.

41 Dlugos DJ, Sammel MD, Strom BL, et al. Response to first drug trial predicts outcome in childhood temporal lobe epilepsy. Neurology 2001;57:2259-64.

42 Kwan P, Brodie MJ. Effectiveness of first antiepileptic drug. Epilepsia 2001;42:1255-60.

43 Brodie MJ, Kwan P. Staged approach to epilepsy management. Neurology 2002;58(suppl 5):S2-8.

44 Siddiqui A, Kerb R, Weale ME, et al. Association of multidrug resistance in epilepsy with a polymorphism in the drug-transporter gene $A B C B 1$. N Engl J Med 2003;348:1442-8.

45 Walz R, Castro RM, Velasco TR, et al. Surgical outcome in mesial temporal sclerosis correlates with prion protein gene variant. Neurology 2003;61:1204-10.

46 Britton JW. Antiepileptic drug withdrawal: literature review. Mayo Clin Proc 2002;77:1378-88.

47 Berg AT, Shinnar S. Relapse following discontinuation of antiepileptic drugs: a meta-analysis. Neurology 1994;44:601-8.
48 Anon. Randomised study of antiepileptic drug withdrawal in patients in remission. Medical Research Council Antiepileptic Drug Withdrawal Study Group. Lancet 1991;337:1175-80.

49 Loscher W, Honack D, Rundfeldt C. Antiepileptogenic effects of the novel anticonvulsant levetiracetam (ucb L059) in the kindling model of temporal lobe epilepsy. J Pharmacol Exp Ther 1998;284:474-9.

50 Pitkanen A. Drug-mediated neuroprotection and antiepileptogenesis: animal data. Neurology 2002;59(suppl 5):S27-33.

51 Wolf SM, Forsythe A. Epilepsy and mental retardation following febrile seizures in childhood. Acta Paediatr Scand 1989:78:291-5.

52 Rosman NP, Colton T, Labazzo J, et al. A controlled trial of diazepam administered during febrile illnesses to prevent recurrence of febrile seizures. N Engl J Med 1993;329:79-84.

53 Temkin NR, Dikmen SS, Wilensky AJ, et al. A randomized, double-blind study of phenytoin for the prevention of post-traumatic seizures. N Engl J Med 1990;323:497-502.

54 Temkin NR, Dikmen SS, Anderson GD, et al. Valproate therapy for prevention of posttraumatic seizures: a randomized trial. J Neurosurg 1999;91:593-600.

55 Foy PM, Chadwick DW, Rajgopalan N, et al. Do prophylactic anticonvulsant drugs alter the pattern of seizures after craniotomy? J Neurol Neurosurg Psychiatry 1992;55:753-7.

56 Camfield C, Camfield P, Gordon K, et al. Does the number of seizures before treatment influence ease of control or remission of childhood epilepsy? Not if the number is 10 or less. Neurology 1996;46:41-4.

57 Musicco M, Beghi E, Solari A, et al. Treatment of first tonic-clonic seizure does not improve the prognosis of epilepsy. First Seizure Trial Group (FIRST Group). Neurology 1997;49:991-8.

58 Feksi AT, Kaamugisha J, Sander JW, et al. Comprehensive primary health care antiepileptic drug treatment programme in rural and semi-urban Kenya. ICBERG (International Community-based Epilepsy Research Group). Lancet 1991;337:406-9.

59 Placencia M, Shorvon SD, Paredes V, et al. Epileptic seizures in an Andean region of Ecuador. Incidence and prevalence and regional variation. Brain 1992;115:771-82.

60 Placencia M, Sander JW, Roman M, et al. The characteristics of epilepsy in a largely untreated population in rural Ecuador. J Neurol Neurosurg Psychiatry 1994;57:320-5.

61 Wang WZ, Wu JZ, Wang DS, et al. The prevalence and treatment gap in epilepsy in China: an ILAE/IBE/WHO study. Neurology 2003;60:1544-5.

62 WHO. http://who.int/country/chn/en/. Accessed 6 May 2003.

63 Keranen T, Riekkinen PJ. Remission of seizures in untreated epilepsy. BMJ 1993;307:483.

64 Kwan P, Brodie MJ. Issues of medical intractability for surgical candidacy. In: Wyllie E, editor. The treatment of epilepsy: principles and practice, 4th ed. Philadelphia: Lippincott Williams and Wilkins, in press.

65 Peters AC, Brouwer OF, Geerts AT, et al. Randomized prospective study of early discontinuation of antiepileptic drugs in children with epilepsy. Neurology 1998;50:724-30.

66 Brodie MJ, Mohanraj R. Pharmacological outcomes in newly diagnosed epilepsy. Epilepsia 2003;44(suppl 8):S84.

67 Kobayashi E, Lopes-Cendes I, Guerreiro CA, et al. Seizure outcome and hippocampal atrophy in familial mesial temporal lobe epilepsy. Neurology 2001;56: 166-72

68 Fuerst D, Shah J, Shah A, et al. Hippocampal sclerosis is a progressive disorder: a longitudinal volumetric MRI study. Ann Neurol 2003;53:413-16.

69 Holmes GL. Seizure-induced neuronal injury: animal data. Neurology 2002;59(suppl 5):S3-6.

70 Duncan JS. Seizure-induced neuronal injury: human data. Neurology 2002;59(suppl 5):S15-20.

71 Berg AT, Langfitt J, Shinnar S, et al. How long does it take for partial epilepsy to become intractable? Neurology 2003;60:186-90.

72 Brodie MJ, Kwan P. The star systems: overview and use in determining antiepileptic drug choice. CNS Drugs 2001;15:1-12.

73 Kwan P, Brodie MJ. Drug treatment of epilepsy: when does it fail and how to optimize its use? CNS Spectr 2004;9:110-19. 